\title{
The Observed Effects of Utility-Scale Photovoltaics on Near-Surface Air Temperature and Energy Balance
}

\author{
ASHLEy M. BROADBENT \\ School of Geographical Sciences and Urban Planning, and Urban Climate Research Centre, \\ Arizona State University, Tempe, Arizona \\ E. SCOTT KRAYENHOFF \\ School of Geographical Sciences and Urban Planning, and Urban Climate Research Centre, Arizona State University, \\ Tempe, Arizona, and School of Environmental Sciences, University of Guelph, Guelph, Ontario, Canada \\ MATEi GeORGeSCU AND DAVID J. SAILOR \\ School of Geographical Sciences and Urban Planning, and Urban Climate Research Centre, and \\ Global Institute of Sustainability, Arizona State University, Tempe, Arizona
}

(Manuscript received 16 October 2018, in final form 7 February 2019)

\begin{abstract}
Utility-scale solar power plants are a rapidly growing component of the renewable energy sector. While most agree that solar power can decrease greenhouse gas emissions, the effects of photovoltaic (PV) systems on surface energy exchanges and near-surface meteorology are not well understood. This study presents data from two eddy covariance observational towers, placed within and adjacent to a utility-scale PV array in southern Arizona. The observational period (October 2017-July 2018) includes the full range of annual temperature variation. Average daily maximum $1.5-\mathrm{m}$ air temperature at the $\mathrm{PV}$ array was $1.3^{\circ} \mathrm{C}$ warmer than the reference (i.e., non-PV) site, whereas no significant difference in 1.5-m nocturnal air temperature was observed. PV modules captured the majority of solar radiation and were the primary energetically active surface during the day. Despite the removal of energy by electricity production, the modules increased daytime net radiation $Q^{*}$ available for partitioning by reducing surface albedo. The PV modules shift surface energy balance partitioning away from upward longwave radiation and heat storage and toward sensible heat flux $Q_{H}$ because of their low emissivity, low heat capacity, and increased surface area and roughness, which facilitates more efficient $Q_{H}$ from the surface. The PV modules significantly reduce ground heat flux $Q_{G}$ storage and nocturnal release, as the soil beneath the modules is well shaded. Our work demonstrates the importance of targeted observational campaigns to inform process-based understanding associated with PV systems. It further establishes a basis for observationally based PV energy balance models that may be used to examine climatic effects due to large-scale deployment.
\end{abstract}

\section{Introduction}

Anthropogenic emissions associated with traditional fossil fuel energy sources have adverse effects on global climate and regional air quality. Global warming and associated climate impacts, driven primarily by greenhouse gas (GHG) emissions, can negatively impact human health (Patz et al. 2005), energy use (Li et al. 2012), ecosystems (Walther et al. 2002; Hoegh-Guldberg and Bruno 2010), infrastructure (Tol 2002), and food security

\footnotetext{
Corresponding author: Ashley M. Broadbent, ashley.broadbent@ asu.edu
}

(Schmidhuber and Tubiello 2007; Wheeler and von Braun 2013). In addition to these impacts, pollutants associated with combustion of fossil fuels, such as particulate matter, are well known to cause regional increases in human mortality and morbidity (Chen et al. 2013). Concern about these impacts has led many to argue that a broad increase in renewable energy sources is needed.

Renewable energy systems are becoming more attractive as increased efficiency drives down the cost of electricity production from renewable sources. Renewable energy provided $17 \%$ of U.S. electricity production in 2017, which represents a $61 \%$ increase in renewable electricity production since 2012 (EIA 2018a). 
The largest electricity providers are hydropower-derived $(44 \%)$ and wind-derived (37\%) energy. Collectively, all solar power sources provided $8 \%$ of renewable electricity in 2017. However, solar is the fastest growing renewable energy sector. Utility-scale solar power plants (capacity $>$ $5 \mathrm{MW}$ ) are growing particularly rapidly; utility-scale photovoltaic (PV) solar power generation in the United States increased by 52\% during 2017 (EIA 2018b). This expansion is likely to continue as the cost of PV technologies further decreases. To ensure new PV systems are environmentally sustainable, it is important that the impacts of such systems are holistically evaluated. This involves considering not only the GHG reductions (biogeochemical impacts), but also local impacts on surface climate and hydrology associated with land surface change (biogeophysical impacts) (Uludere Aragon et al. 2017).

Biogeophysical impacts are local and driven by surface mass and energy balance modifications that occur because of changes in surface attributes such as vegetation coverage and albedo. Local biogeophysical impacts are distinct from the more commonly considered biogeochemical impacts, which are driven primarily by GHG gas emissions. Life cycle analysis studies suggest biogeochemical benefits of renewable energy systems vary considerably (Lenzen and Munksgaard 2002; Pacala and Socolow 2004; Fthenakis and Alsema 2006; Pehnt 2006; Wang et al. 2007; Hsu et al. 2012), but the consensus is that renewable energy systems can reduce GHG emissions relative to fossil fuel energy sources. Less clearly understood are the characteristics and relative magnitude of local-geophysical impacts caused by renewable energy and implications for surface hydrology and climate.

Regional climate modeling has been used to assess the geophysical effects of PV installations. Studies of rooftop $\mathrm{PV}$ have found local daytime air temperature cooling $\left(0.2^{\circ}-0.4^{\circ} \mathrm{C}\right)$ and nighttime cooling $\left(0.3^{\circ}-0.7^{\circ} \mathrm{C}\right)$ during summer conditions (Taha 2013; Masson et al. 2014; Salamanca et al. 2016), while simulations of utilityscale installations have found both cooling ( $\mathrm{Hu}$ et al. 2016) and warming (Millstein and Menon 2011) effects. Representation of solar modules in climate models is simplistic and it is typical that only radiative fluxes are assumed modified, via altered surface albedo and emissivity. Observations suggest that PV modules reduce reflected shortwave $K \uparrow$ and emitted longwave radiation $L \uparrow$ during summer conditions, relative to a barren site (Chang et al. 2018). Masson et al. (2014) developed a rooftop PV model, which solves the radiative balance of horizontal solar modules assuming that PV temperature is equal to air temperature. Their approach is the most sophisticated PV energy balance model currently available for modeling the geophysical effects of solar modules. However, the model contains assumptions that require evaluation, underscoring the need for more complete observational data. Other surfaceatmosphere processes potentially affected by PV modules remain poorly understood and are neglected in PV land surface modeling. For example, the effects of PV installations on surface roughness and resulting turbulent heat transfer require consideration.

Recent observational work further highlights the uncertainty around local biogeophysical effects of PV on surface climate. Barron-Gafford et al. (2016) observed air temperature at a utility-scale PV array in southern Arizona to be warmer than a nearby reference station throughout the year and across the diurnal cycle. The authors called this effect the PV heat island (PVHI), drawing comparison to the urban heat island (UHI). The PVHI was observed to be larger at night $\left(3^{\circ} \mathrm{C}\right)$ than during the day $\left(\sim 1.5^{\circ} \mathrm{C}\right)$. The Barron-Gafford et al. (2016) results appear to contradict findings from modeling studies, which predict air temperature cooling associated with rooftop (Taha 2013; Masson et al. 2014; Salamanca et al. 2016) and utility-scale (Hu et al. 2016) PV systems. The discrepancy suggests there are shortcomings with current PV modeling approaches; however, these shortcomings are difficult to assess because Barron-Gafford et al. (2016) do not assess the drivers of their measured PVHI, nor do they report the height of their measurements. The full surface energy balance (including turbulent fluxes) associated with PV arrays has not been measured, and to our knowledge, it has not been a focus of any other research effort. Thus, detailed understanding of the surface energy balance of PV arrays and of potential impacts on local surface climate (including PVHI) remains unknown. Understanding of the mechanisms by which PV arrays influence the surface energy balance is needed for the development of reliable PV surface energy balance models.

This study presents findings from two eddy covariance observational towers, placed within and directly adjacent to a utility-scale PV array in southern Arizona during a 9-month period from October 2017 to July 2018. A range of ancillary observations, including air temperature measurements at different heights, are made concurrently to support surface energy balance measurements. The primary goal of this study is to explain the energy balance processes modified by PV arrays, and their impacts (principally in terms of air temperature) on local surface climate.

\section{Methods}

a. Site

Measurements were taken at the Arizona Public Service (APS) Red Rock solar power plant $\left(32^{\circ} 33^{\prime} 16.6^{\prime \prime} \mathrm{N}\right.$, $111^{\circ} 17^{\prime} 03.7^{\prime \prime} \mathrm{W}$ ), which is located approximately $50 \mathrm{~km}$ 


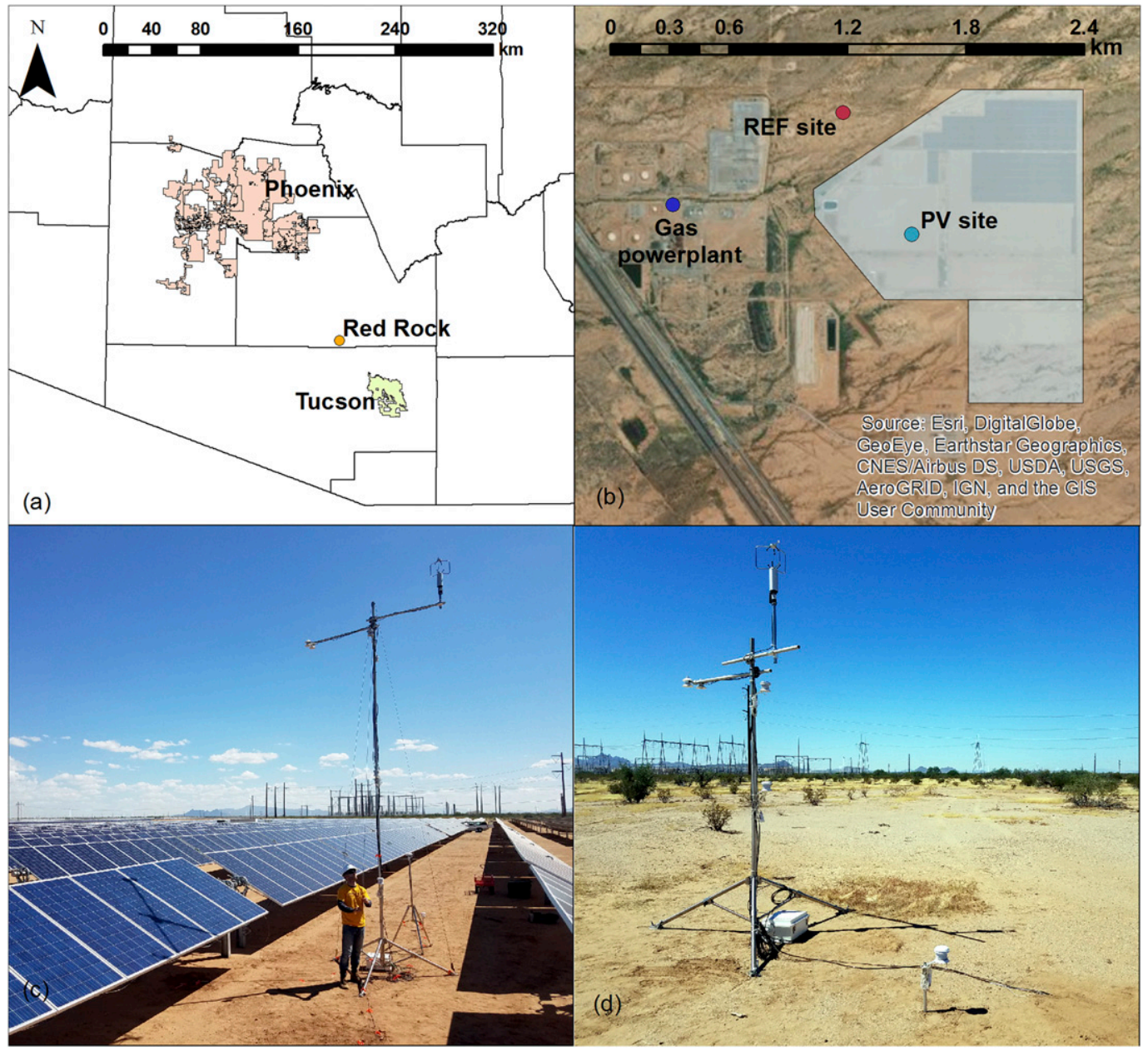

FIG. 1. Map and photographs showing (a) location of Red Rock solar power plant in southern Arizona, (b) Red Rock solar power plant site (blue shading) and surrounding area, (c) PV measurement site, and (d) reference measurement site.

northwest of Tucson, Arizona (Fig. 1a). The power plant is predominately surrounded by open shrubland terrain. Outside the PV power plant, sporadic Sonoran vegetation, including creosote, saguaro cacti, and palo verde, are in situ. The PV array is located approximately $1 \mathrm{~km}$ east of a natural gas-fired power plant (APS). This orientation and the prevailing southeasterly winds rarely place the PV array downwind of the power plant.

The Red Rock PV power plant occupies a total area of approximately 162 ha (Fig. 1b). The facility has a 40-MW capacity, with 182880 solar modules operating on site. The modules are Trina TSM-PD14 and are mounted on an automated single-axis tracking system. When the PV modules are horizontal, the plan area fraction of PV module coverage is 0.45 . The ground beneath the modules is bare soil and completely devoid of vegetation; APS periodically removes any vegetation growing on the site.

\section{b. Instruments and experiment design}

Two towers (Campbell Scientific CM110 and CM120 tripods) were deployed at the Red Rock site (Figs. 1c,d). One tower was set up in the PV array and a reference tower (i.e., non-PV) was erected over unmodified desert approximately $300 \mathrm{~m}$ northwest of the site. The height of each tower was 6 and $3 \mathrm{~m}$ for the PV and reference sites, respectively (mounting heights of all instruments are given in Table 1). The higher tower at the PV site ensured that instruments were mounted at 3 times the maximum PV module height, which ensures relevant turbulent structures are captured (Kastner-Klein and Rotach 2004). The heights of both 3D sonic anemometers and net radiometers were chosen to ensure representative source areas were captured at both sites. With the assumption of homogenous source areas is met, we expect negligible impacts associated with different mounting heights given the magnitude of measured 
TABLE 1. Summary of instrument specifications at the PV and reference sites. Letters in parentheses in the PV site section refer to Fig. 2.

\begin{tabular}{|c|c|c|c|c|}
\hline Instrument & $\begin{array}{l}\text { Variable(s) } \\
\text { measured }\end{array}$ & $\begin{array}{l}\text { Height or depth } \\
\text { deployed }(\mathrm{m})\end{array}$ & Accuracy & $\begin{array}{l}\text { Sampling } \\
\text { frequency }\end{array}$ \\
\hline \multicolumn{5}{|l|}{ PV site } \\
\hline $\begin{array}{l}\text { (a) Campbell scientific } \\
\text { CS220-L/CS240 thermocouples }\end{array}$ & $\begin{array}{l}\text { PV surface } \\
\quad \text { temperature } T_{\text {module }}\end{array}$ & $\begin{array}{l}\text { Adhered to underside } \\
\text { of PV module }\end{array}$ & - & $10 \mathrm{~s}$ \\
\hline (b) Onset HOBO Pro v2 (shielded) & $\begin{array}{l}\text { Air temperature, } \\
\text { relative humidity }\end{array}$ & $0.4,1.5,2.7^{\mathrm{a}}, 3.2$ & $0.5^{\circ} \mathrm{C}$ & $5 \mathrm{~min}$ \\
\hline $\begin{array}{l}\text { (c) Decagon DS-2 2D sonic } \\
\text { anemometer }\end{array}$ & $\begin{array}{l}\text { Wind direction, } \\
\text { wind speed }\end{array}$ & $0.4,1.8$ & $\begin{array}{r}1^{\circ}(\text { direction }) \\
3 \% \text { (speed })\end{array}$ & $10 \mathrm{~s}$ \\
\hline $\begin{array}{l}\text { (d) Campbell scientific TCAV-L } \\
\text { soil thermocouple }\end{array}$ & Soil temperature $T_{\text {soil }}$ & $0.02-0.06$ & $\sim 0.5^{\circ} \mathrm{C}$ & $10 \mathrm{~s}$ \\
\hline (d) Huxeflux HFP01 soil heat flux plate & $Q_{G}$ & 0.08 & $\pm 15 \%$ & $10 \mathrm{~s}$ \\
\hline (e) RM Young 8100 sonic anemometer & $3 \mathrm{D}$ wind $Q_{H}$ & 6.3 & $\begin{array}{l} \pm 2^{\circ}(\text { direction }) \\
\quad \pm 1 \%(\text { speed })\end{array}$ & $20 \mathrm{~Hz}$ \\
\hline (f) NR01-L 4-Component net radiometer & $K \downarrow, K \uparrow, L \downarrow, L \uparrow$ & 5.7 & $\pm 10 \%$ (daily total) & $10 \mathrm{~s}$ \\
\hline \multicolumn{5}{|l|}{ Reference site } \\
\hline Onset HOBO Pro v2 (shielded) & $\begin{array}{l}\text { Air temperature, } \\
\text { relative humidity }\end{array}$ & $0.4,1.5,2.7$ & $0.5^{\circ} \mathrm{C}$ & $5 \mathrm{~min}$ \\
\hline $\begin{array}{l}\text { Campbell scientific TCAV-L } \\
\text { soil thermocouple }\end{array}$ & Soil temperature $T_{\text {soil }}$ & $0.02-0.06$ & $\sim 0.5^{\circ} \mathrm{C}$ & $10 \mathrm{~s}$ \\
\hline Huxeflux HFP01 soil heat flux plate & $Q_{G}$ & 0.08 & $\pm 15 \%$ & $10 \mathrm{~s}$ \\
\hline RM Young 8100 sonic anemometer & 3D wind $Q_{H}$ & 3.3 & $\begin{array}{l} \pm 2^{\circ} \text { (direction) } \\
\quad \pm 1 \% \text { (speed) }\end{array}$ & $20 \mathrm{~Hz}$ \\
\hline NR01-L 4-Component net radiometer & $K \downarrow, K \uparrow, L \downarrow, L \uparrow$ & 2.8 & $\pm 10 \%$ (daily total) & $10 \mathrm{~s}$ \\
\hline $\begin{array}{l}\text { Campbell Scientific CS616 } \\
\text { soil moisture sensor }\end{array}$ & $\begin{array}{l}\text { Volumetric water } \\
\text { content }\end{array}$ & 0.06 & $\begin{array}{l} \pm 2.5 \% \text { volumetric } \\
\text { water content }(\mathrm{VWC})\end{array}$ & $5 \mathrm{~min}$ \\
\hline
\end{tabular}

${ }^{\mathrm{a}}$ The 2.7-m sensor was installed on 5 December 2017.

radiation fluxes. Radiative longwave flux divergence/ convergence may have a small impact on net radiometers mounted at different heights; based on measurements by Steeneveld et al. (2010), 2-5 $\mathrm{W} \mathrm{m}^{-2}$ of longwave flux convergence/divergence can occur over a 10 -m layer. However, our measured differences in midday upward longwave flux density are almost an order of magnitude larger.

Given the size of the array and the prevailing wind (easterly to southeasterly), and assuming PV modules are not thermally heterogeneous, we postulate that our assumption of directional homogeneous source area at the PV site is satisfactory. For the reference site, our siting was more restrictive given limited suitable locations nearby for safe deployment of the tower. The most suitable site was about $300 \mathrm{~m}$ downwind (prevailing conditions) of the PV modules (Fig. 1b). Contamination of air temperature at the reference site due to advection from the PV array is treated as negligible and is addressed in the appendix (see Fig. A1).

A schematic representation of the tower setup is shown in Fig. 2. Measurements of air temperature and humidity (Onset HOBO Pro v2 sensors) were made at three heights at each site (see Table 1 for full summary of instruments). In addition, the temperature of the underside of PV modules $T_{\text {module }}$ and soil $T_{\text {soil }}$ were monitored. Soil sensors were buried (depths of 2 and $6 \mathrm{~cm}$ ) at both shaded and unshaded locations at the PV site (Fig. 2). The instrumentation deployed provided measurement of the surface energy balance, defined as

$$
\begin{aligned}
Q^{*} & =(L \downarrow-L \uparrow)+(K \downarrow-K \uparrow) \\
& =Q_{G}+Q_{H}+Q_{E}+Q_{\mathrm{PV}}+Q_{A} .
\end{aligned}
$$

Net radiation $Q^{*}$ is a function of downwelling $(\downarrow)$ and upwelling ( $\uparrow$ ) shortwave $K$ and longwave $L$ radiation fluxes. Net radiation $Q^{*}$ is partitioned into ground heat flux $Q_{G}$, sensible heat flux $Q_{H}$, latent heat flux $Q_{E}$, energy absorbed by PV modules and converted to electricity $Q_{\mathrm{PV}}$, and horizontal advection $Q_{A}$. The $Q^{*}$ components were measured with Huxeflux NR01-L net radiometers. After processing the radiation data, we noticed that there was a systematic difference in $K \downarrow$ between the reference and PV sites. The discrepancy in $\Delta K \downarrow(\mathrm{PV}-$ reference $)$ was as high as $+30 \mathrm{~W} \mathrm{~m}^{-2}$ during the morning and $-30 \mathrm{~W} \mathrm{~m}^{-2}$ during afternoon. Assessment of $K \downarrow$ measurements from each site separately suggests the nonzero $\Delta K \downarrow$ is likely due to the PV site net radiometer being slightly off level for part of the experiment. It is likely that the net radiometer arm shifted slightly because of wind and tension on the tripod mast. The PV site net radiometer was mounted at $6.3 \mathrm{~m}$ above 


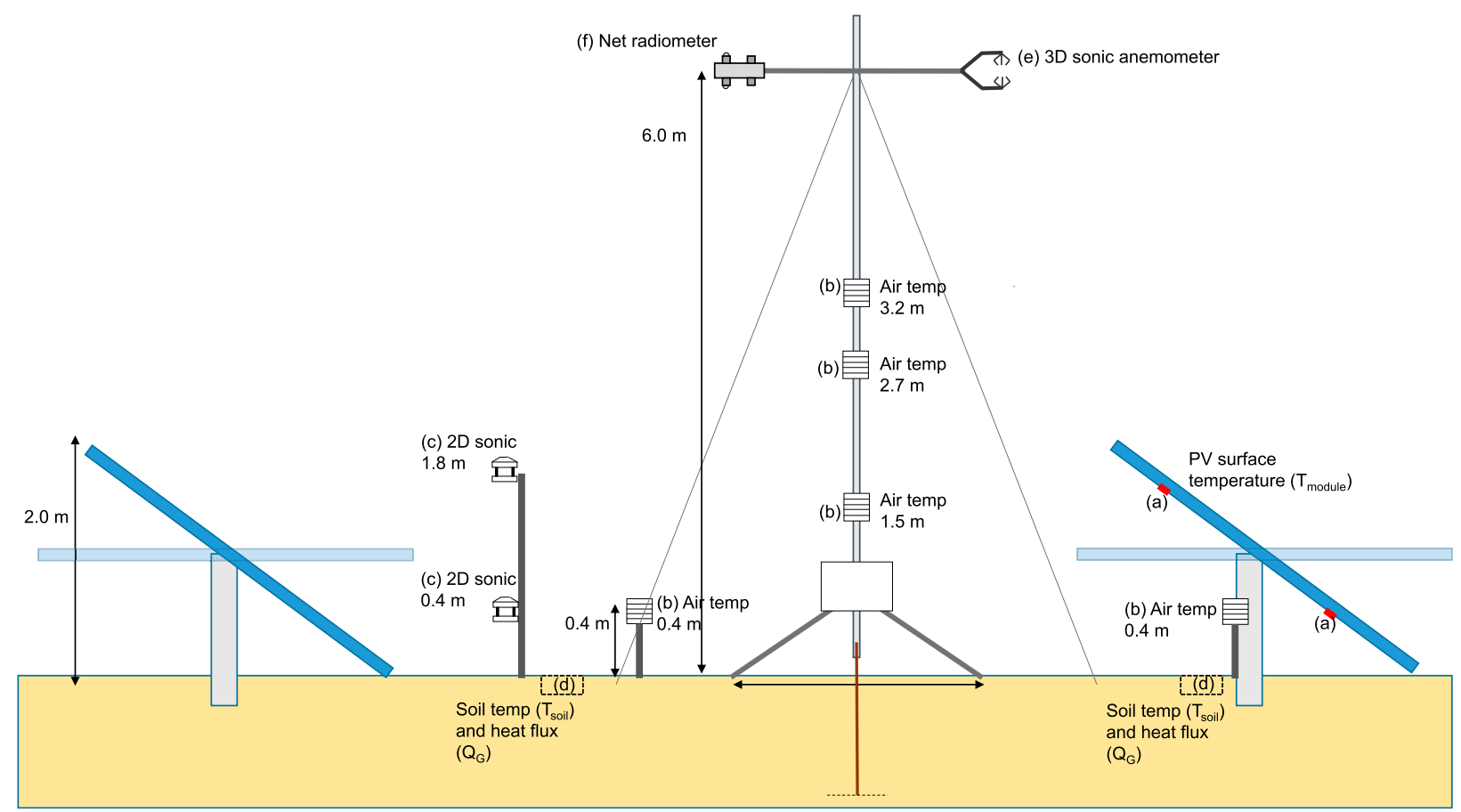

FIG. 2. Schematic of the PV site and instrumentation used. A full summary of instrument specifications for both sites is provided in Table 1.

ground and thus could not easily be checked as level once the mast was lifted. The other arms of the tripod and sensors were not affected. To avoid errors associated with the PV net radiometer, we use the reference site $K \downarrow$ in this paper. This is a reasonable assumption, given the proximity of the sites (Fig. 1), and we therefore expect no intersite variation in $K \downarrow$. The longwave fluxes and $K \uparrow$ were less affected by off-level mounting since they exhibit far less directionality compared to $K \downarrow$, and we use those fluxes as measured.

We measured $Q_{G}$ with Huxeflux HFP01 heat flux plates, and to account for heat storage above the flux plates this parameter was calculated as

$$
Q_{G}=\left(\frac{\Delta T_{\text {soil }} C_{s} d}{t}\right)+Q_{\mathrm{Gr}}
$$

where $Q_{\mathrm{Gr}}$ is the raw heat flux measurement, $\Delta T_{\text {soil }}$ is the change in soil temperature over the previous 30-min period, $C_{s}$ is the soil heat capacity (assumed as $1.28 \mathrm{MJ} \mathrm{m}^{-3} \mathrm{~K}^{-1}$ for a sandy soil, as predominant across the region; Oke et al. 2017), $d$ is the measurement depth $(0.08 \mathrm{~m})$, and $t$ is the time interval $(1800 \mathrm{~s})$. The two $Q_{G}$ measurements (shaded and unshaded, see Fig. 2) are then weighted as follows: at night (PV modules are stowed at an angle of $30^{\circ}$ ), we assume a weighted mean of the two measurements, based on the plan area fraction of PV modules $F_{\mathrm{PV}}$. During the day, we calculate the shadow length for each 30-min period, assuming PV modules are perpendicular to the solar angle, and weight the $Q_{G}$ measurements accordingly.

During a 2-week period in October 2017 the reference site soil heat flux sensor was dug up by burrowing animals. These data were filled in using the objective hysteresis model (OHM) (Grimmond et al. 1991; see appendix and Fig. A2 for details). The value of $Q_{\mathrm{PV}}$ was calculated from the following:

$$
Q_{\mathrm{PV}}=\frac{E}{A_{\mathrm{PV}}} F_{\mathrm{PV}},
$$

where $E$ is the total power produced by the PV array (W) obtained from APS, $A_{\mathrm{PV}}$ is the total active (i.e., upper PV surface) area of $\mathrm{PV}$ modules $\left(\mathrm{m}^{2}\right)$, and $F_{\mathrm{PV}}$ is the plan area fraction of $\mathrm{PV}$ modules, which varies with PV angle. For $Q_{H}$ measurement, RM Young $8100 \mathrm{ul}-$ trasonic 3D anemometers were used. The $Q_{H}$ measurements were processed using the Licor EddyPro software. The following corrections were included: axis for tilt rotation (Wilczak et al. 2001) and other quality control checks (Mauder and Foken 2006). Air temperature and relative humidity (30-min averages) from the HOBO instruments (measured at approximately same height as ultrasonic anemometers) were provided to the EddyPro software, so that the sonic temperature was not used during $Q_{H}$ data processing. (A full assessment of energy balance closure for both sites is provided in the appendix and Fig. A3.) 
TABLE 2. Summary of weather conditions at the Marana Regional Airport (MesoWest) weather station for the study observational period. In the last column, the value in parentheses indicates the number of days with measured precipitation. There were two monsoon events days during early July in which $57 \mathrm{~mm}$ of rainfall fell. The high winds that accompanied these monsoon events led to the decision to takedown the towers.

\begin{tabular}{|c|c|c|c|c|c|}
\hline Period & $\begin{array}{l}\text { Average max air } \\
\text { temperature }\left({ }^{\circ} \mathrm{C}\right)\end{array}$ & $\begin{array}{l}\text { Average min air } \\
\text { temperature }\left({ }^{\circ} \mathrm{C}\right)\end{array}$ & $\begin{array}{l}\text { Average min wind } \\
\text { speed }\left(\mathrm{m} \mathrm{s}^{-1}\right)\end{array}$ & $\begin{array}{l}\text { Average max wind } \\
\text { speed }\left(\mathrm{m} \mathrm{s}^{-1}\right)\end{array}$ & Total precipitation $(\mathrm{mm})$ \\
\hline All & 28.3 & 12.8 & 1.5 & 6.8 & 105.2 (16 days) \\
\hline Fall & 26.7 & 11.3 & 1.5 & 5.8 & 10.9 (2 days) \\
\hline Winter & 21.9 & 7.3 & 1.5 & 6.6 & 24.9 (9 days) \\
\hline Spring & 34.7 & 17.9 & 1.5 & 7.5 & 12.2 (2 days) \\
\hline
\end{tabular}

HOBO temperature probes (with radiation shields) were tested prior to deployment. They were deployed in outdoor setting (enclosed courtyard) for 3 days. The instruments were within specified instrument accuracies for most conditions. However, despite the use of radiation shields, warm biases $\left(>0.5^{\circ} \mathrm{C}\right)$ occurred when instruments were exposed to high radiation loads (i.e., 1100-1500 local time) during low wind conditions $\left(<0.25 \mathrm{~m} \mathrm{~s}^{-1}\right)$. Such problems have been previously documented by Erell et al. (2005). As such, we attempted to ensure all air temperature probes deployed during the experiment were exposed to the same radiation (i.e., the shield was fully exposed to sunlight) to ensure biases cancel. Further, we believe the relatively high wind speeds at the site ensure adequate ventilation for all sensors mounted above $1.5 \mathrm{~m}$. However, for HOBOs mounted at ground level $(0.4 \mathrm{~m})$, we could not ensure uniform radiation exposure and adequate wind ventilation at the PV site. For the PV site, we deployed two HOBOs at ground level, one directly below PV modules (predominately shaded) and one between the PV modules (predominately unshaded); PV site 0.4-m air temperatures in this paper are averages of both ground-level sensors.

\section{c. Observational period}

Air temperature observations were recorded continuously for the period from 26 September 2017 to 11 July 2018. All times listed in this paper are given in the local time zone for Arizona: mountain standard time (MST). To characterize the observational period, data from the Marana Regional airport, located $16.5 \mathrm{~km}$ southeast of the Red Rock site were obtained from MesoWest (see Table 2). The 9-month period was characterized by predominately clear-sky conditions, with a total of 16 days where precipitation was recorded. Rain days were omitted from energy balance calculations, as $Q_{E}$ was not measured. During fall and winter, the local wind regime was characterized by two prevailing wind directions (Fig. 3). During the day (0600-1700 MST), the flow was typically directed from the southeast or northwest (Fig. 3). Whereas during evening and nighttime (1800-0500 MST) hours, the wind direction was most commonly observed from the sector $45^{\circ}-135^{\circ}$ (Fig. 3). Prevailing winds during spring shifted to the southwest during both day and night hours.

\section{Results}

\section{a. Overview of dataset}

Surface energy balance data for the period from 26 September 2017 to 11 July 2018 were collected (Fig. 4). Gaps in the dataset occurred because of instrument and battery failure, and rain and high wind events. Instrument maintenance was challenging since access to the site was limited because an APS escort was required. Additionally, the towers had to be lowered during thunderstorm conditions to protect APS assets from possible damage. The analysis below exclusively includes periods where data from both sites were available.

\section{b. Air temperature}

Figure 5a shows a time series of 1.5 -m air temperature for the period from 26 September 2017 to 11 July 2018. This period coincides with fall (1 October-31 December), winter (1 January-31 March), and spring (1 April-30 June) in southern Arizona. Summer (1 July-31 September) in Arizona roughly corresponds with the North American monsoon and frequent thunderstorms; the PV tower could not be safely maintained during this period. Nevertheless, warm weather conditions (above $40^{\circ} \mathrm{C}$ ) were captured during May and June 2018 (Fig. 5a).

The average 1500 MST $1.5-\mathrm{m}$ air temperature was $1.3^{\circ} \mathrm{C}$ warmer at the PV site (Fig. $5 b$ ). A positive afternoon PVHI (i.e., PV air temperature $>$ reference air temperature) occurred on every day during the observational period (Fig. 5c). The magnitude of the average afternoon PVHI varied from $1.1^{\circ} \mathrm{C}$ during winter to $1.6^{\circ} \mathrm{C}$ during spring, which is consistent with the findings of Barron-Gafford et al. (2016). The magnitude of this afternoon warming effect tended to be larger on hotter days, exceeding $3.0^{\circ} \mathrm{C}$ on some occasions (Fig. 5c). However, daily maximum air temperature can only explain $19 \%$ of the variability in PVHI intensity, indicating 

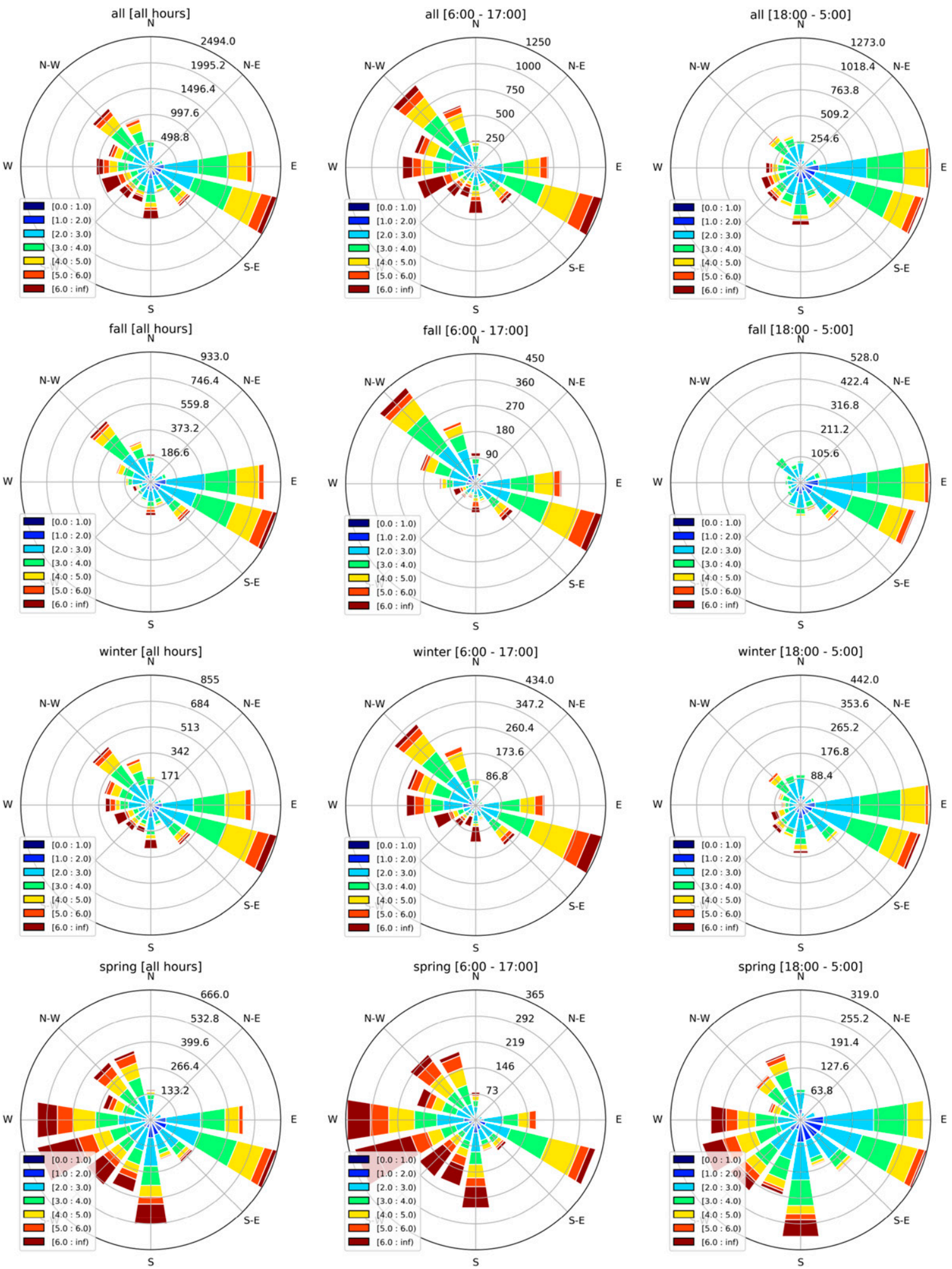

FIG. 3. Wind roses for (top) entire observational period (26 Sep 2017-11 Jul 2018), (second row) fall (1 Oct-31 Dec 2017), (third row) winter (1 Jan-31 Mar 2018), and (bottom) spring (1 Apr-30 Jun 2018). The columns show wind roses for (left) all hours, (center) 06001700 MST, and (right) 1800-0500 MST. These data were obtained from the nearby Marana Regional Airport MesoWest weather station. 


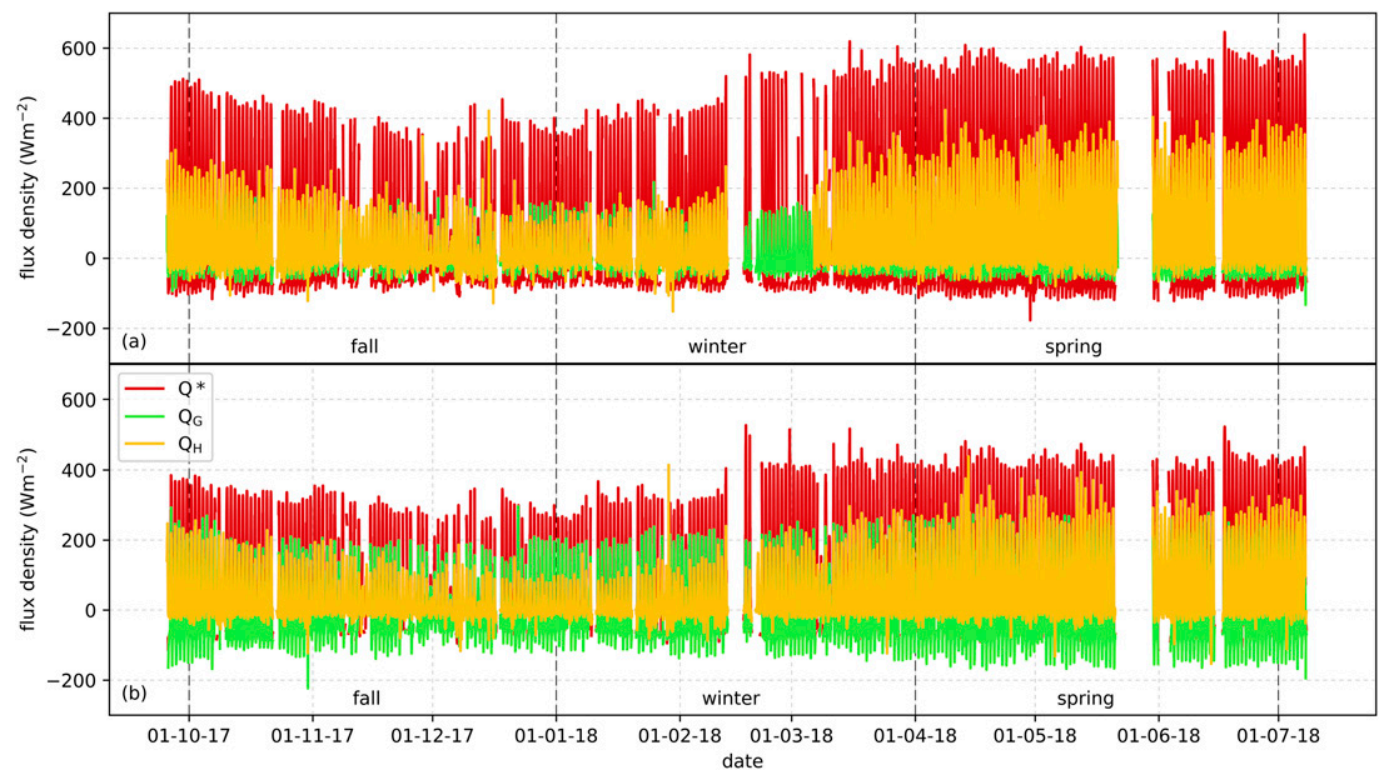

FIG. 4. Time series overview of surface energy balance fluxes for the period 26 Sep 2017-11 Jul 2018 for (a) PV site and (b) reference site.

that wind speed, cloud cover, and other factors also play a role.

For nocturnal hours our results indicate no significant difference in the 1.5-m air temperature between the two sites. This result contrasts with Barron-Gafford et al. (2016), who found an average midnight PVHI of $3^{\circ}-4^{\circ} \mathrm{C}$ throughout the year. However, the PV array observed by
Barron-Gafford et al. (2016) is smaller and less continuous than the Red Rock array. Their PV air temperature measurement was contained within a continuous field of PV modules with a horizontal extent no larger than 2 ha $(\sim 230 \mathrm{~m} \times 90 \mathrm{~m})$. There are also structures and impervious surfaces within $30 \mathrm{~m}$ of the edge of the solar modules, suggesting their air temperature measurements may
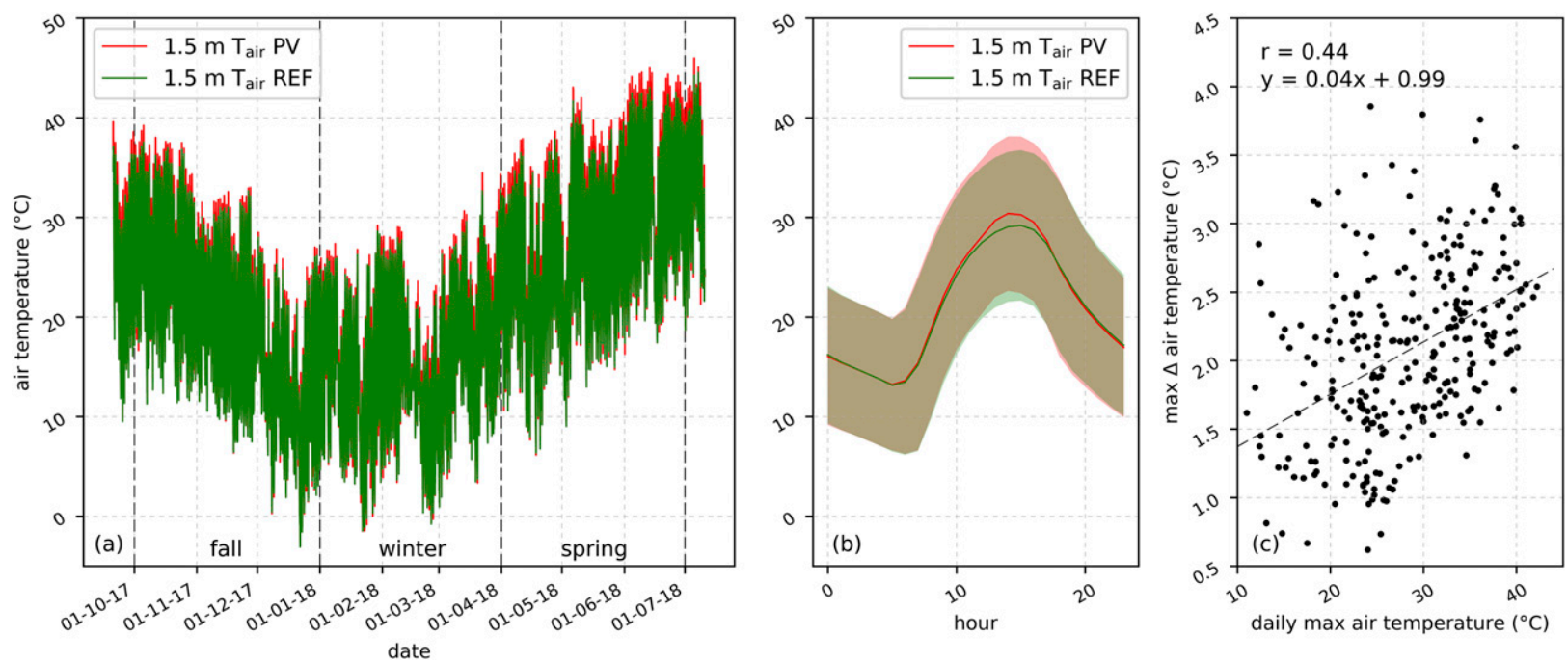

FIG. 5. (a) Time series of observed air temperature (1.5 m) at the PV (red) and reference (green) sites for the period 26 Sep $2017-11$ Jul 2018; (b) the diurnal average air temperature (1.5 m) at the PV (red) and reference (green) sites for the period 26 Sep 2017-11 Jul 2018, where hour indicates local time (MST) from midnight to midnight; and (c) the daily maximum air temperature (Marana Airport) vs the daily maximum temperature difference between the PV and reference sites (PV - REF). In (b) the color-shaded areas show the standard deviation of each curve and in (c) $r$ is the correlation coefficient. Mean diurnal maximum $\mathrm{PV}-\mathrm{REF}$ air temperature was $1.3^{\circ} \mathrm{C}$; in fall it was $1.1^{\circ} \mathrm{C}$, in winter $1.2^{\circ} \mathrm{C}$, and in spring $1.6^{\circ} \mathrm{C}$. 


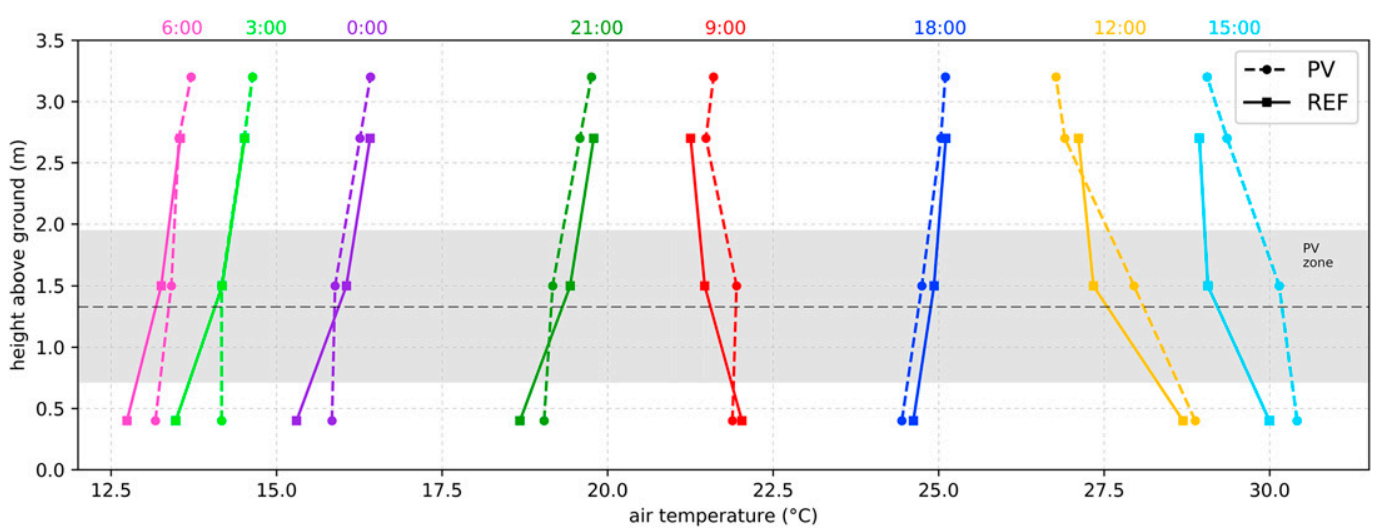

FIG. 6. Near-surface air temperature profiles demonstrating average air temperature with height above the ground throughout the diurnal cycle. The averaged profiles represent the period from 26 Sep 2017 to 11 Jul 2018. Squares with a solid line correspond to the reference site, and circles with a dashed line correspond to the PV site. Profiles are color coded by local time and labeled at the top of figure (MST). The gray-shaded area represents the maximum and minimum PV module height throughout the diurnal cycle. The $2.7-\mathrm{m}$ air temperature at the PV site was installed $5 \mathrm{Dec}$ 2017; data at $2.7 \mathrm{~m}$ before this date were obtained by linear interpolation between 1.5- and 3.2-m measurements. The 0.4-m air temperature is an average of two measurements (shaded and unshaded) at the PV site. However, because of instrument failure, the 0.4-m air temperature is taken from a single instrument during 12 Dec-9 Jan and 31 May-18 Jun.

have been affected by advection from adjacent impervious areas. Furthermore, because they do not report the height of their measurements, a direct comparison to our observed air temperatures is not possible.

We investigate the average vertical profile of air temperature (Fig. 6), which reveals a more complex picture than the $1.5-\mathrm{m}$ air temperature. A nocturnal stable layer did not form below $1.5 \mathrm{~m}$ at the PV site, as the modules likely enhance vertical turbulent mixing and impede longwave radiative cooling at night. As such, average nocturnal air temperature at $0.4 \mathrm{~m}$ was $\sim 0.5^{\circ} \mathrm{C}$ warmer than the reference site. Nocturnal air temperature differences below PV height varied seasonally with maximum values during fall $\left(\sim 1.0^{\circ} \mathrm{C}\right)$ and minimum values during winter $\left(\sim 0.35^{\circ} \mathrm{C}\right)$. During the afternoon hours, the difference in 1.5 - $\mathrm{m}$ air temperature between the sites was larger than at $2.7 \mathrm{~m}$, suggesting that the PV heating effect is vertically constrained to the air directly adjacent to the solar modules. To further elucidate the controls on air temperature we next present detailed results from surface energy balance fluxes.

\section{c. Radiation balance}

The average difference between the two sites indicates that daytime $Q^{*}$ was higher at the PV site than the reference, with an average maximum $\Delta Q^{*}$ (PV reference) of $104.5 \mathrm{~W} \mathrm{~m}^{-2}$ (Fig. 7). The maximum $\Delta Q^{*}$ was greater during spring $\left(132.0 \mathrm{~W} \mathrm{~m}^{-2}\right)$ than winter $\left(89.2 \mathrm{~W} \mathrm{~m}^{-2}\right)$ and fall $\left(81.0 \mathrm{~W} \mathrm{~m}^{-2}\right)$ (see Figs. $\left.7 \mathrm{~d}-\mathrm{f}\right)$. The intersite difference in $Q^{*}$ was primarily due to a lower $K \uparrow$ at the PV site relative to the reference site. The reduced $K \uparrow$ derives from the lower average surface albedo at the PV site (0.20) compared to the reference site (0.31), meaning less $K \downarrow$ is reflected back to the atmosphere at the PV site; these albedo values were consistent across all seasons observed. With regard to the longwave radiation fluxes, the PV site had a lower average daytime $L \uparrow$ than the reference (Fig. 7c). The average minimum daytime $\Delta L \uparrow$ was $-21.4 \mathrm{~W} \mathrm{~m}^{-2}$ and ranged from $-15.1 \mathrm{~W} \mathrm{~m}^{-2}$ (winter) to $-31.1 \mathrm{~W} \mathrm{~m}^{-2}$ (spring) throughout the observational period. In contrast, nighttime $\Delta L \uparrow$ was positive with an average maximum of $10.2 \mathrm{~W} \mathrm{~m}^{-2}$. Overall, both short- and longwave radiative fluxes are consistent with the findings of recent work from Chang et al. (2018).

The longwave radiation dynamics are likely a result of three interrelated factors: 1) the differing emissivities of sandy soil and PV modules, 2) a kind of cavity effect caused by upward soil reflection of the large downward longwave emission from the panels, and 3) differences in facet surface temperatures. We estimate (using thermal imagery) that the upper-surface of PV modules at Red Rock have a lower emissivity $(\sim 0.83)$ than sandy soil (0.92); while the emissivity of the PV underside is approximately 0.97 . The lower emissivity of the upper PV module surface may partially explain the reduced daytime $L \uparrow$ at the PV site. The higher nighttime $L \uparrow$ at the PV site, relative to the reference site, could be partially driven by the cavity effect. The soil beneath the PV modules reflects $\sim 8 \%$ of the radiation emitted at it by the PV modules, which may increase the $L \uparrow$ at night. Additionally, the surface temperature of different facets plays an important role in determining longwave fluxes and we explore this below. A detailed model of PV 

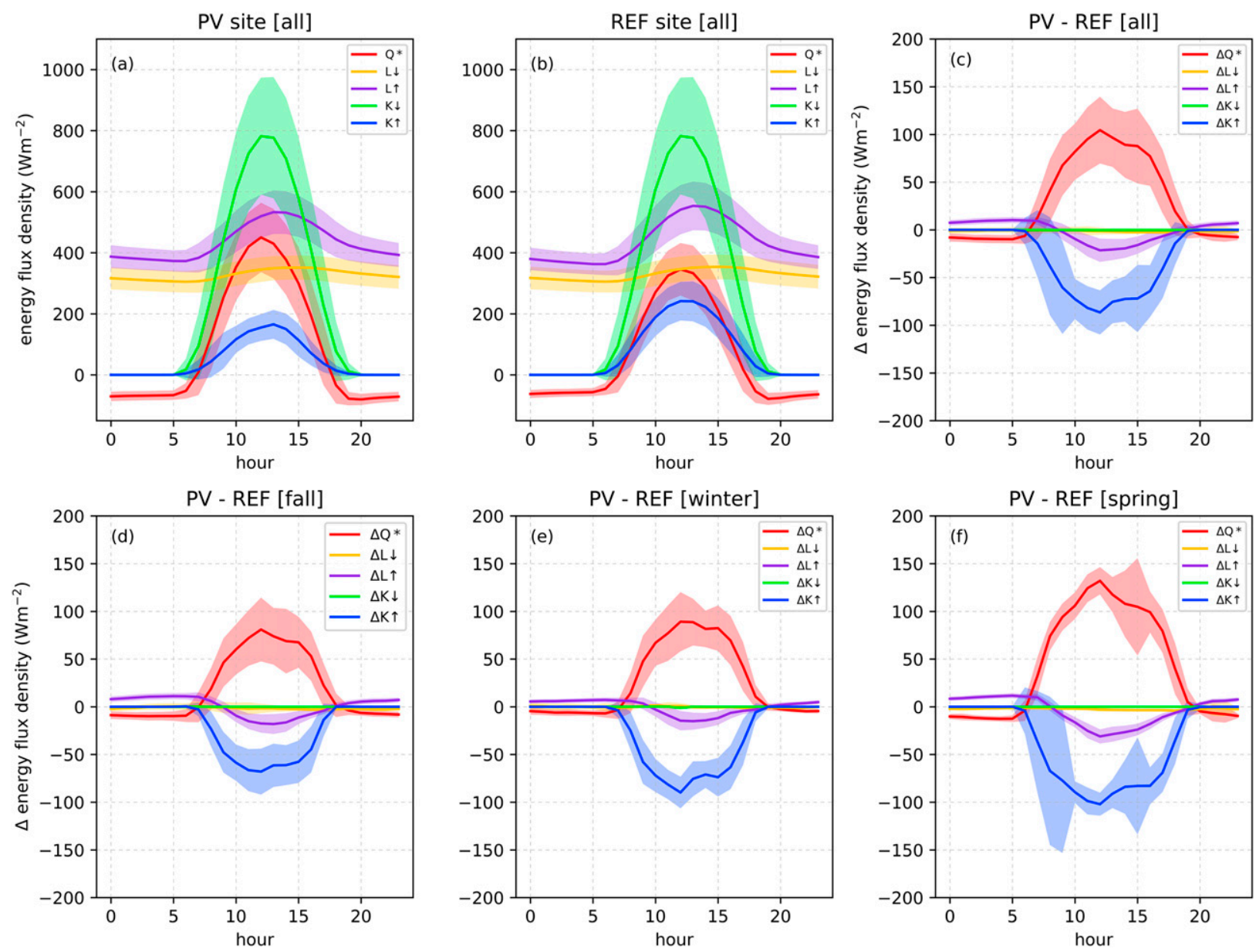

FIG. 7. Diurnally averaged radiative fluxes from the (a) PV and (b) reference sites for 26 Sep 2017-11 Jul 2018. (c)-(f) The difference (PV - REF) in diurnally averaged fluxes for the (c) whole period, (d) fall, (e) winter, and (f) spring. Hour indicates local time (MST) from midnight to midnight, and shaded areas indicate plus and minus one standard deviation about the mean of the corresponding curve.

surface energy balance is needed to fully understand the interplay between these factors.

\section{d. Surface temperatures}

Solar shading keeps the soil cooler beneath the modules during the day; the average shaded $T_{\text {soil }}$ (average of 2-6-cm depth) at the PV site was $9.8^{\circ} \mathrm{C}$ cooler than the average exposed $T_{\text {soil }}$ at the reference site (Fig. $8 \mathrm{c}$, green line). The maximum average $T_{\text {soil }}$ cooling reached $14.8^{\circ} \mathrm{C}$ in spring and dropped to $6.2^{\circ}-7.7^{\circ} \mathrm{C}$ during fall and winter, respectively. By contrast, the nocturnal $T_{\text {soil }}$ measurements at the PV site (exposed and shaded locations) were warmer than the reference $T_{\text {soil. }}$ Nocturnal soil cooling is decreased because of increased mixing and downward transport of sensible heat and/or reduced net longwave $L^{*}$ loss from soil due to lowered ground sky-view factor by the PV modules.

The $T_{\text {soil }}$ measurements are measured at 2-6-cm depth and do not represent the temperature at the soil surface. However, the $L \uparrow$ measurement at the reference site can be converted to a soil surface temperature (REF $T_{\text {avg }}[L \uparrow]$ ), using an assumed emissivity (see purple curve in Fig. $8 \mathrm{~b}$ ). Directly measured $T_{\text {module }}$ (contact thermocouple) was $6.1^{\circ} \mathrm{C}$ cooler than REF $T_{\text {avg }}[L \uparrow]$ at night (Fig. 8c, blue line), suggesting the PV modules have minimal capacity for heat storage compared to unmodified soil. The magnitude of the nocturnal temperature differences between PV modules and soil remained constant across all seasons observed (Figs. 8d-f).

There was a complex relationship between $T_{\text {module }}$ and REF $T_{\text {avg }}[L \uparrow]$ during the day (Fig. 8c): $T_{\text {module was }}$ warmer than REF $T_{\text {avg }}[L \uparrow]$ during the morning and afternoon because the modules are tilted toward the sun and heat up (cool down) faster (slower) than soil during periods with low solar angle. However, at noon the difference between $T_{\text {module }}$ and REF $T_{\text {avg }}[L \uparrow]$ was small, implying that fully exposed sandy soil and PV modules have similar maximum surface temperature, despite PV modules absorbing more solar radiation 

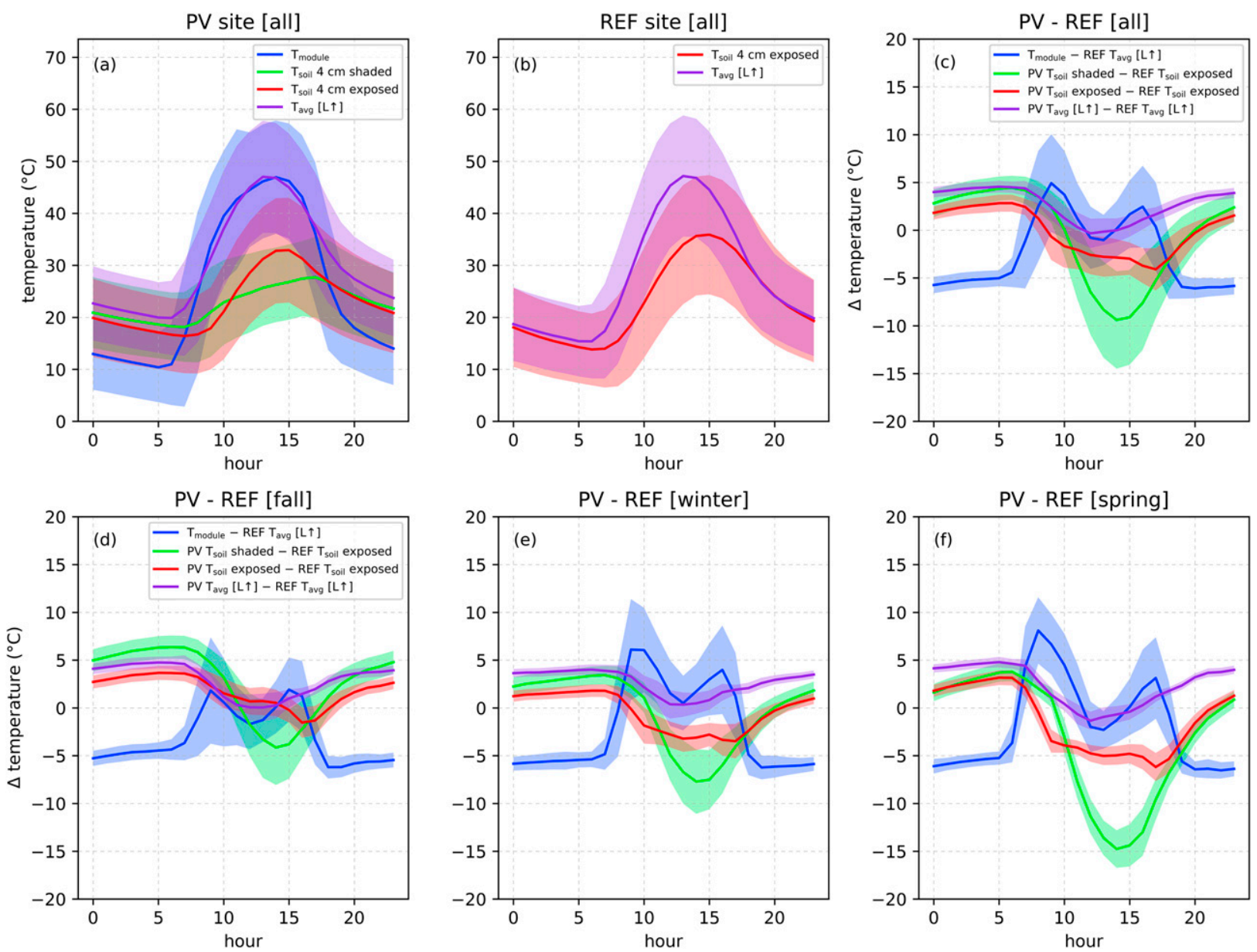

FIG. 8. Average soil and PV module temperatures at (a) PV and (b) reference sites for 26 Sep 2017-11 Jul 2018. (c)-(f) The difference (PV - REF) in diurnally averaged temperatures for the (c) whole period, (d) fall, (e) winter, and (f) spring; hour indicates local time (MST) from midnight to midnight. The value of $T_{\text {module }}$ is calculated as the average of two thermocouples adhered to the PV modules. The $T_{\text {soil }}$ measurements are obtained from the buried thermocouples and represent an average soil temperature for 2-6-cm depths. Finally, $T_{\text {avg }}$ is $L \uparrow$ converted to temperature using weighted emissivities: sandy soil $=0.92$ (Oke et al. 2017) and PV $=0.83$ (measured). Shaded areas indicate plus and minus one standard deviation.

because of solar tracking and low PV albedo. The magnitude of $T_{\text {module }}$ is partially regulated because the conversion of solar radiation to electricity removes some energy [ $\sim 16 \%$ of $K \downarrow$ on a plane perpendicular to the sun (TrinaSolar specifications)] from the system.

The radiative fluxes imply that PV modules increase absorbed shortwave radiation because of a decreased surface albedo relative to the correspondingly reflective semiarid desert landscape. Despite this increase in $Q^{*}$, the maximum daytime $T_{\text {module }}$ was comparable to the surface temperature of exposed sandy soil. Thus, we next explore the partitioning of nonradiative fluxes to fully understand the drivers of PVHI.

\section{e. Nonradiative fluxes}

The difference in surface energy balance fluxes between the two sites is given in Figs. 9c-f. As indicated by the $T_{\text {soil }}$ measurements, shading results in $50-100 \mathrm{~W} \mathrm{~m}^{-2}$ less positive (downward) daytime $Q_{G}$ at the PV site relative to the reference site. This reduced daytime $Q_{G}$ at the PV site also results in $40-70 \mathrm{~W} \mathrm{~m}^{-2}$ less negative (upward) $Q_{G}$ at night as compared to the reference, indicating that the shading from modules reduces the magnitude of $Q_{G}$ fluxes throughout the diurnal cycle. Despite the reduced nocturnal storage heat release by the ground, air temperatures in the near-ground layer remain higher at the PV site throughout the night, suggesting that this warming results from enhanced turbulent mixing and possibly reduced ground skyview factor.

The PV site had slightly more negative nocturnal $Q_{H}$, indicating increased transport of heat from the atmosphere to the surface at the PV site. This increased negative $Q_{H}$ would also explain the less stable (neutral) 

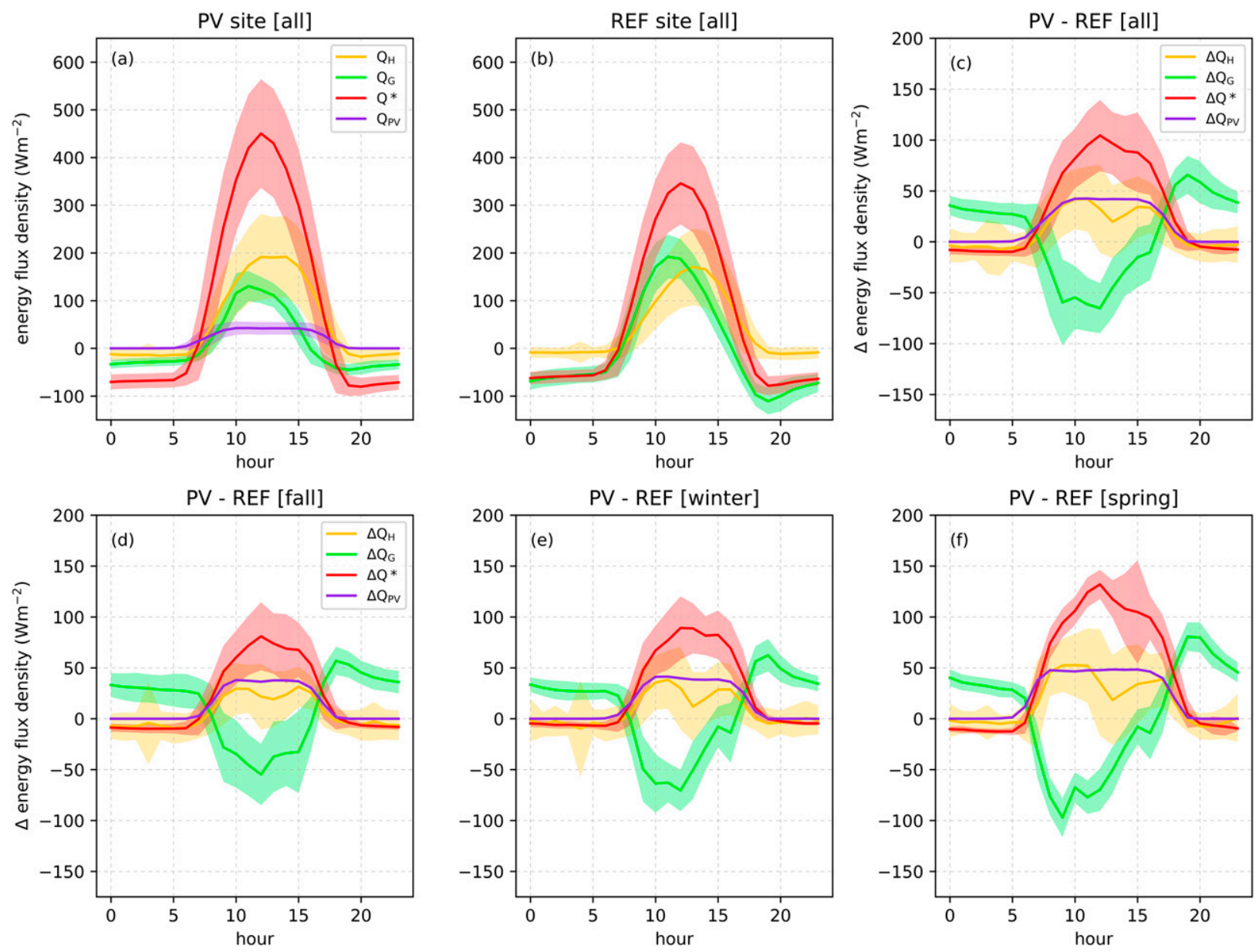

FIG. 9. Average diurnal surface energy balances from the (a) PV and (b) reference sites for 26 Sep 2017-11 Jul; hour indicates local time (MST) from midnight to midnight. (c)-(f) The difference (PV - REF) in diurnally averaged fluxes for the (c) whole period, (d) fall, (e) winter, and (f) spring. Shaded areas show plus and minus one standard deviation of each curve.

layer at the PV site. The modules, which are below air temperature at night, likely become a sink for heat from $Q_{H}$. Further, the modules are stowed at a $30^{\circ}$ tilt at night, which increases surface roughness and could enhance downward transport of heat from the atmosphere to the surface. The downward transport of heat via $Q_{H}$ is likely a key driver of increased nocturnal $L \uparrow$ at the PV site. Last, given the low nocturnal $T_{\text {module }}$, it is possible that $Q_{H}$ at the PV site is more negative than measured. This underprediction of $Q_{H}$ would explain the gap in energy balance closure at the PV site.

The higher daytime $Q^{*}$ at the PV site was partially dissipated through $Q_{\mathrm{PV}}$, which reached a maximum magnitude of $50 \mathrm{~W} \mathrm{~m}^{-2}$ during spring (Fig. 9f). The average $Q_{\mathrm{PV}}$ represents $12.8 \%$ of available daytime $Q^{*}$; this ratio varies seasonally from $15.0 \%, 14.7 \%$, and $11.8 \%$ for fall, winter, and spring, respectively. However, not all the additional $Q^{*}$ can be dissipated as $Q_{\mathrm{PV}}$. The PV site had average daytime $Q_{H}$ that was $25-50 \mathrm{~W} \mathrm{~m}^{-2}$ higher than the reference site. The redirection of energy to $Q_{H}$ is driven by three factors: 1) PV modules have less capability to dissipate this energy via longwave emissions and conduction (i.e., storage); 2) increased surface roughness, due to drag and associated wake production by PV modules, facilitates more efficient upward transport of $Q_{H}$ during the day; and 3) the warm PV modules, which have two sides for $Q_{H}$ to occur (increased surface area), are more exposed to wind allowing efficient convective heat transfer (especially when tilted).

The peaks in $\Delta Q_{H}$ (see Figs. 9c-f) occur in the morning and early afternoon periods when PV modules were titled toward the sun, during the morning and afternoons PV modules have high temperature and create a rougher surface. The two peaks in $\Delta Q_{H}$ reinforce the importance of surface roughness, module temperature, and module tilt in controlling $Q_{H}$ and near-surface air temperature at the PV site. Existing models of PV systems do not account for surface 
roughness effects and may risk under predicting $Q_{H}$, especially for tracking PV systems.

\section{Discussion and conclusions}

\section{a. Key results}

This study presents the first ever measurements of the surface energy balance above a utility-scale PV solar array. We found that average daily maximum $1.5-\mathrm{m}$ air temperature within the array was $1.3^{\circ} \mathrm{C}$ warmer than at an unmodified desert site. Our daytime air temperature results at $1.5 \mathrm{~m}$ are consistent with Barron-Gafford et al. (2016) who also observed a daytime PVHI $\left(1.5^{\circ} \mathrm{C}\right)$ at a utility-scale PV array in southern Arizona. However, Barron-Gafford et al. (2016) observed a large nocturnal PVHI $\left(3.0^{\circ}-4.0^{\circ} \mathrm{C}\right)$. Our results indicate an average nocturnal PVHI of $0.5^{\circ} \mathrm{C}$ below the modules at a height of $0.4 \mathrm{~m}$ and no PVHI effect at $1.5 \mathrm{~m}$. Direct comparison of results with Barron-Gafford et al. (2016) is difficult because they do not report the height of their air temperature measurements. Regardless of measurement height, our nocturnal PVHI results are not consistent with theirs. We postulate that the considerable nocturnal PVHI effect measured by Barron-Gafford et al. (2016) was partially caused by advection from nearby urban surfaces at their University of Arizona site.

The present study provides a clear account of how PV systems impact the vertical profile of near-surface air temperature throughout the diurnal cycle. In addition, surface energy balance observations and other ancillary measurements reveal and clarify the modified surface energy balance processes that lead to PVHI. We have identified seven modified processes affected by PV modules. Below we summarize theses key processes separately for both nighttime and daytime.

Daytime impacts:

1) $P V$ modules become the primary energetically active surface. PV modules largely replace ground as active energy exchange surface, especially in the morning and afternoon when their tilt captures most of the incident solar radiation and shades the soil surface. As a result, all energy balance fluxes are reduced in magnitude at the ground (soil) surface relative to the ground surface at the reference site.

2) $P V$ modules increase energy driving the surface energy balance (i.e., increased $Q^{*}$ ). PV modules amplify the energy available to drive the surface energy balance per plan area, because the increase in shortwave radiation absorption (due to lower module albedo relative to local soils) is larger than PV energy production (related to current energy conversion efficiencies).
3) $P V$ modules partition energy preferentially toward $Q_{H}$. PV modules shift surface energy dissipation away from heat storage (including $Q_{G}$ ) and $L \uparrow$ because of their lower heat capacity and reduced emissivity relative to soil, respectively. The modules instead channel energy toward $Q_{H}$, resulting from a probable combination of (i) larger resistance to heat storage and $L \uparrow$, (ii) greater roughness and turbulence generation (i.e., mixing) due to the canopy of modules, and (iii) greater exposure of hot module surfaces to wind due to module tilting and the two-sided nature of the modules (i.e., increased surface area).

4) Increased $P V$ module $Q_{H}$ warms a vertically discrete air layer. The larger $Q_{H}$ from the $\mathrm{PV}$ modules appears to create a vertically limited "warm layer" directly adjacent the PV modules at approximately $1-2 \mathrm{~m}$ above the ground.

Nighttime impacts:

5) PV modules increase nocturnal net longwave radiation loss. The canopy composed of PV modules and ground surface increases overall $L \uparrow$ despite their lower surface temperature and emissivity, presumably because of reflections between ground and PV modules (i.e., a cavity effect) and higher soil surface temperatures.

6) PV modules reduce surface storage heat flux release and increase sensible heat flux gain. Less daytime heat is stored in soils because of shading from PV panels, which themselves offer negligible heat storage. The roughness introduced by the PV canopy likely increases downward $Q_{H}$ from aloft; hence, a milder stable layer forms above the PV panels than over the reference site ground. Modules become sinks for heat from $Q_{H}$ because their temperature falls below air temperature.

7) PV modules maintain warmer, neutral conditions below them. PV modules maintain a higher air temperature near the ground and neutral near-surface stability within the canopy because of enhanced mixing (as in point 6, above) and possibly because of longwave trapping of soil $L \uparrow$.

We expect points $1,3,4,6$, and 7 to be generalizable to other sites and PV module types, whereas points 2 and 5 are potentially dependent on the characteristics of local background soils (and vegetation) and the state of PV technology.

\section{b. Implications}

Overall, the effects of PV arrays on surface climate are likely to vary across different climates, regions, and individual PV array characteristics (e.g., module type, spacing, and tracking). This study confirms that PV 
systems can create warmer daytime air temperature when placed over desert surfaces with relatively high albedo, such as those found in southern Arizona. The modules reduced albedo by 0.11 , which led to increased $Q^{*}$ during daylight hours (point 2, above). However, the albedo at the reference site (i.e., southern Arizona desert) is higher than most natural surfaces. We suggest that an increase in $Q^{*}$ is not a universal characteristic of PV systems and could be avoided if PV modules are deployed over surfaces with lower albedo, including impervious surfaces in urban areas and/or if PV conversion efficiency to electricity is increased. For example, previous work using building energy balance models has shown that PV modules will provide local cooling when placed on a dark roof but will lead to warming when installed on a white roof (Scherba et al. 2011). Given that PV modules can lead to a decrease in surface albedo, closer attention should be given to these tradeoffs.

Energy balance measurements reveal that the difference in $Q^{*}$ between the sites is roughly equal to the difference in $Q_{H}$ plus $Q_{\mathrm{PV}}$. In broad terms, surplus energy not converted to electricity is transferred back to the atmosphere as heat (points 2 and 3, above). Given the physical properties of currently available PV modules, this finding is likely to be universal. However, future modules with greater solar efficiency, higher emissivity and/or heat storage capacity, may result in less $Q_{H}$ transfer to the atmosphere, and a smaller daytime geophysical warming impact.

PV shading causes cooler soil temperature during the day and slightly warmer soil temperature at night. One might expect a nocturnal PV cooling effect due to reduced upward $Q_{G}$ at night. However, increased mixing and increased ground-level sky-view factor, due to the PV module canopy (see points 6 and 7 above), may drive below module air temperature. Nevertheless, reduced magnitude of surface $Q_{G}$ fluxes is likely to be a universal characteristic of PV modules. Reduced $Q_{G}$ may mitigate nocturnal heat in urban areas if impervious materials with high thermal admittance are shaded by PV modules.

\section{c. Limitations}

A limitation of this study was the relatively short time period of surface energy balance observations (September 2017-July 2018), including no observations from the North American monsoon. However, this is not a major concern as the full range of annual temperature variation, including hot weather (May and June 2018) conditions were capture. Additionally, instrument accuracy is an unavoidable limitation in observational studies. The HOBO air temperature sensors and HFP01 flux plates have the largest uncertainties relative to the measured effects. However, the magnitudes of the intersite differences were at least double the magnitude of instrument accuracy, raising confidence in our reported values. The proximity of the reference site to the array was another caveat that bears mentioning. Unfortunately, no other suitable locations for the reference site could be located. Nevertheless, comparison between northeasterly and southwesterly conditions suggests that the downstream impacts at the reference site were negligible (see appendix). Finally, the energy balance closure at the PV site was less comprehensive than the reference site. We hypothesize this discrepancy is caused, in part, by horizontal advection, and we are conducting a horizontal transect of air temperature measurements to assess this hypothesis.

\section{d. Future work}

This study has shown the PV arrays can impact air temperature when placed above high albedo desert, indicating that environmental assessment of new utilityscale PV array could include an assessment of possible local surface climate impacts. However, more sophisticated models of PV surface energy balance and canopy processes are needed if accurate examination of their large-scale deployment is to be undertaken. Principally, effects of surface roughness/aerodynamic drag on vertical heat exchange processes should be included to accurately capture surface energy balance characteristics. Improved representation of the physical processes associated with PV surface energy balance will allow more accurate representation of the impacts of PV arrays on surface meteorology and climate, including local heating or cooling impacts. We are currently developing a new PV energy balance model using observational data from the Red Rock site. Additionally, the new PV model will help us precisely ascertain the interplay between modified energy exchange processes caused by PV systems, especially at night.

The present study primarily evaluated the effects of PVHI within the vicinity of the PV power plant. Although downstream impacts on air temperature appear to be minimal, future work is needed to assess how large-scale PV implementations affect local climates of areas downstream. Coupled regional climate models, such as the Weather Research Forecasting (WRF) Model, may be useful for evaluating the downstream impacts of large-scale uptake of PV systems in different climates and environments. Finally, the geophysical impacts of PV systems must also be 


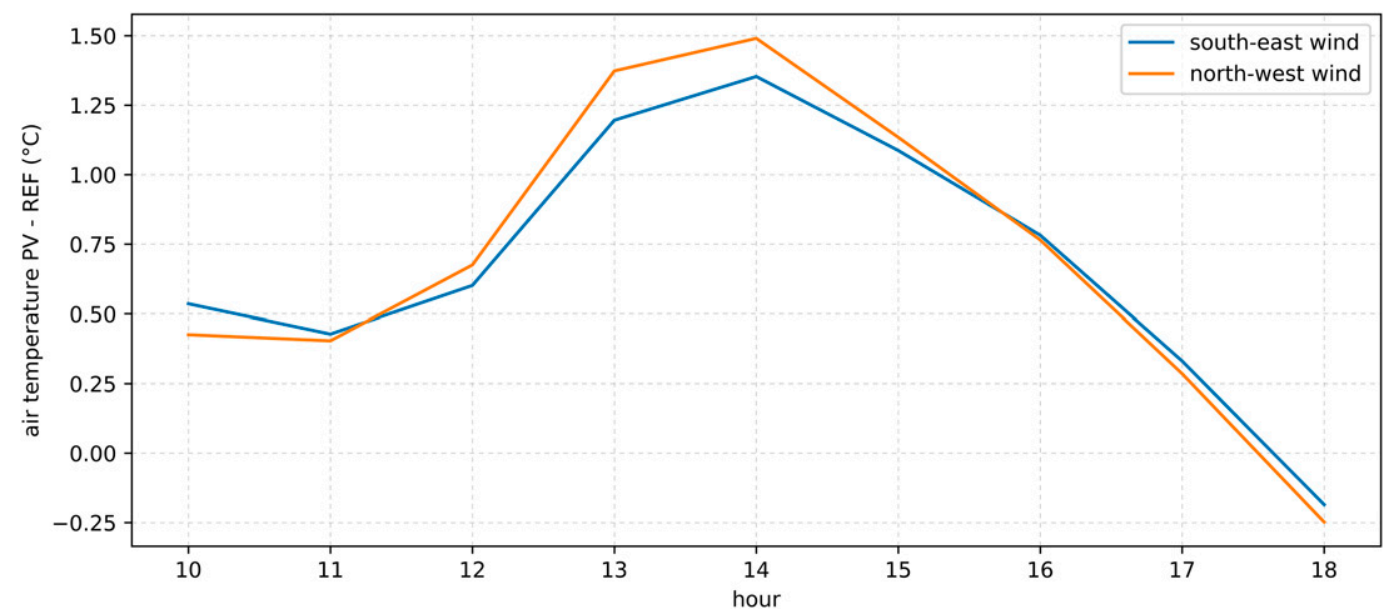

FIG. A1. Average daytime (1000-1800 MST) air temperature (1.5 m) difference, for the period 26 Sep 2017-11 Jul 2018, between the PV and reference sites for southeasterly and northwesterly winds. During southwesterly winds the reference site is downwind of PV array.

evaluated against geochemical benefits of reduced anthropogenic emissions.

Acknowledgments. This work was supported at Arizona State University by the National Science Foundation Sustainability Research Network (SRN) Cooperative Agreement 1444758, SES-1520803, and EAR-1204774. The authors would also like to express their gratitude to the Arizona Public Service for allowing access to the Red Rock solar power station, to Peter Crank, Amir Baniassadi, and Jannik Heusinger for assistance with sensor deployment, to Ian McHugh, Ben Crawford, and Andreas Christen for technical advice, and to Sean Evans for logistical assistance.

\section{APPENDIX}

\section{Downwind Impacts of PV Array at Reference Site}

To assess the impact of the PV array on downstream air temperature we compared PVHI (PV air temperature minus reference air temperature) for southeasterly and northwesterly winds. The reference site was located $300 \mathrm{~m}$ northwest of the PV modules. Thus, if we compare the day PVHI intensity (PV - REF site), for southeasterly and northwesterly wind, we can approximate the downstream impact at the reference site (Fig. A1). Figure A1 shows the average air temperature difference for the hours from 1000 through 1800 MST. These results suggest there is a $0.25^{\circ} \mathrm{C}$ downstream impact at the reference site. The magnitude of this effect was small and within the bounds of instrument accuracy. However, this temperature difference does imply that the array is influencing air temperature downwind of the array. The downstream effects of PV arrays should be explored further with additional observations and modeling.

\section{a. Ground heat flux $Q_{G}$ gap filling}

Because of animal interference with soil instruments, the OHM (Grimmond et al. 1991) was used to calculate reference site $Q_{G}$ for the period 9-23 October:

$$
\Delta Q_{G}=\sum_{i=1}^{n} a_{1} Q^{*}+\sum_{i=1}^{n} a_{2}\left(\frac{\partial Q^{*}}{\partial t}\right)+\sum_{i=1}^{n} a_{3},
$$

where $t=$ time $(\mathrm{s}),\left(\partial Q^{*} / \partial t\right)=0.5\left(Q_{t-1}^{*}-Q_{t+1}^{*}\right)$, and the values of $a_{1}-a_{3}$ were $0.43,0.27$, and -42.4 (after Asaeda and Ca 1993). We evaluated this approach against observations for one month directly proceeding the instrument failure period and found satisfactory agreement (Fig. A2).

We did not measure $Q_{E}$, as it was assumed negligible given the dry conditions (see Table 2; rainfall days were filtered out of the dataset) and lack of vegetation at the site.

\section{b. Energy balance closure assessment}

To evaluate energy balance closure, we calculate regression coefficients using ordinary linear regression (OLR) for $Q_{H}+Q_{\mathrm{PV}}$ against $Q^{*}-Q_{G}$ (Fig. A3). We assume $Q_{E}=0$, which, given the lack of rainfall and vegetation and very low soil moisture $(<0.05 \%$ volumetric water content), is likely a valid assumption. In addition, we calculated the energy balance ratio (EBR) after Mahrt (1998): 


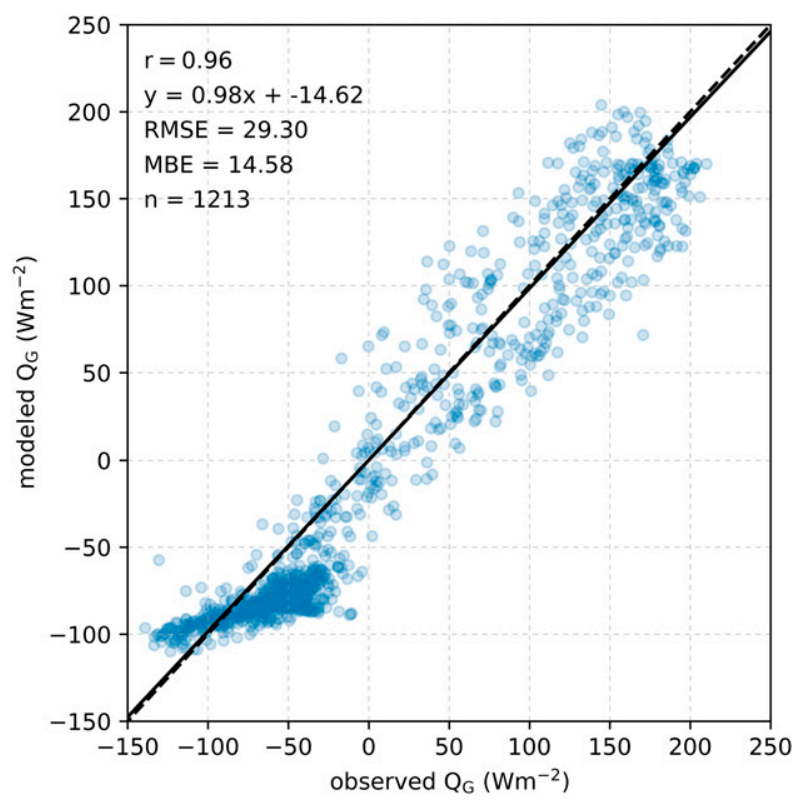

FIG. A2. OHM-derived $Q_{G}$ against observed $Q_{G}$ for the period 24 Oct-24 Nov 2017. OHM was used to calculate reference site $Q_{G}$ for the period 9-23 Oct 2017 because of soil instrument failure.

$$
\mathrm{EBR}=\frac{\sum\left(Q_{H}+Q_{\mathrm{PV}}\right)}{\sum\left(Q^{*}-Q_{G}\right)} .
$$

Statistics reported in Fig. A3 are comparable to those reported in previous eddy covariance studies (Wilson et al. 2002; Offerle et al. 2005; Chow et al. 2014). The slope of the linear regression models and the root-mean-square errors (RMSE) at the reference site were more accurate than those at the PV site. However, reference site EBR (0.75) was lower than at the PV site (0.89), and in line with those reported at Flux Network (FLUXNET) sites (Wilson et al. 2002). The PV site overestimates the magnitude of nocturnal fluxes and underestimates daytime fluxes, and the EBR statistic does not account for these diurnal biases.

Lack of energy balance closure is common in eddy correlation studies, for several potential reasons (Wilson et al. 2002). We hypothesize that $Q_{H}$ (negative at night and positive during the day) could be underpredicted by the sonic anemometers, particularly at the PV site. Underpredictions of $Q_{H}$ are common on eddy covariance studies (Leuning et al. 2012). Further, we suspect some of the unaccounted-for energy is due to a net advection of heat downwind of the array. Although the PV tower was placed in the middle of a large PV array with uniform surface characteristics in all directions, the downwind portion of the array could be warmer than upwind. Fthenakis and $\mathrm{Yu}$ (2013) showed using computational fluid dynamics (CFD) calculations that the air temperature of the downwind edge of a PV array is warmed (because of horizontal advection) as air moves across the warm and elevated PV fetch. Under such conditions, $Q_{A}$ upwind of the sensor is weaker than $Q_{A}$ downwind of the sensor, leading to a horizontal energy divergence. If there is a substantial difference in $Q_{A}$ upwind and downwind of the control volume, one could not expect energy balance closure.
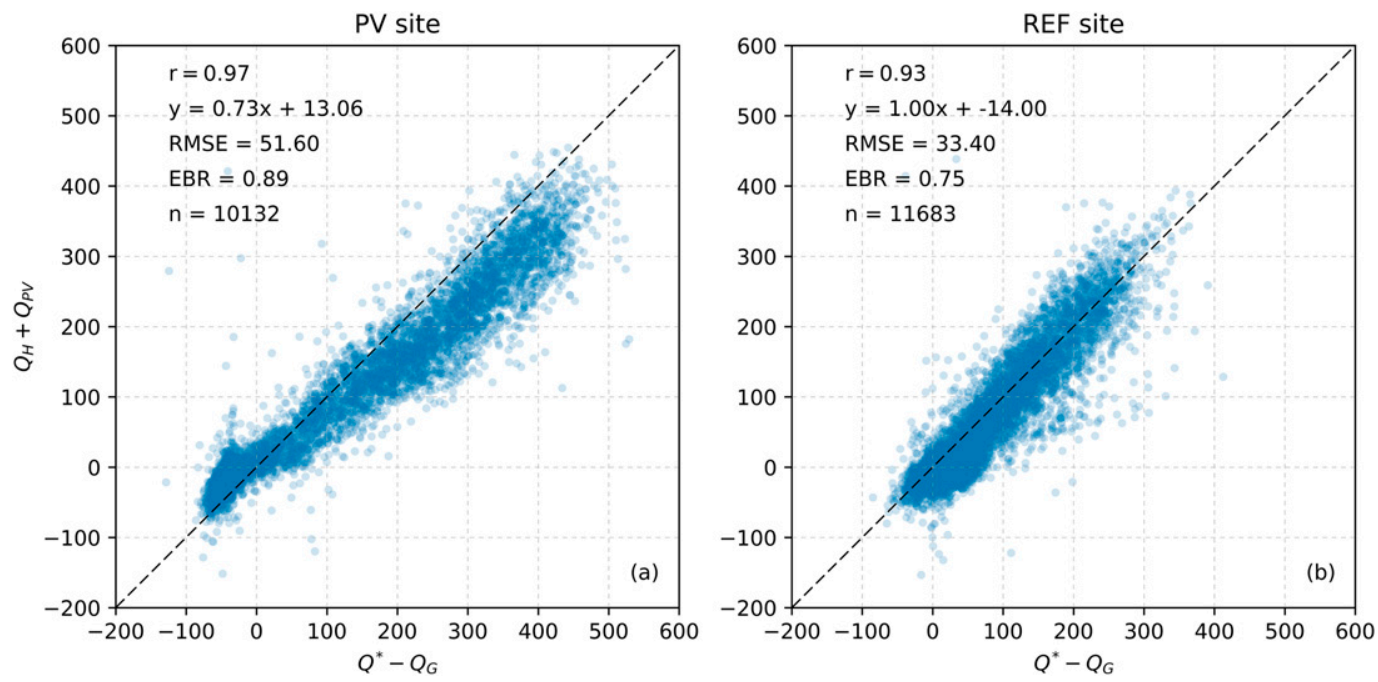

FIG. A3. Energy balance closure assessment for 26 Sep 2017-11 Jul 2018 at (a) PV and (b) reference sites. Ordinary linear regression of $Q_{H}+Q_{\mathrm{PV}}$ against $Q^{*}-Q_{G}$ is used to calculate statistics reported: $r$ is the correlation coefficient, RMSE is the root-mean-square error, $n$ is the number of observations, and $\mathrm{EBR}=\left[\sum\left(Q_{H}+Q_{\mathrm{PV}}\right)\right] /\left[\sum\left(Q^{*}-Q_{G}\right)\right]$. 


\section{REFERENCES}

Asaeda, T., and V. T. Ca, 1993: The subsurface transport of heat and moisture and its effect on the environment: A numerical model. Bound.-Layer Meteor., 65, 159-179, https://doi.org/ 10.1007/BF00708822.

Barron-Gafford, G. A., R. L. Minor, N. A. Allen, A. D. Cronin, A. E. Brooks, and M. A. Pavao-Zuckerman, 2016: The photovoltaic heat island effect: Larger solar power plants increase local temperatures. Sci. Rep., 6, 35070, https://doi.org/10.1038/ srep35070.

Chang, R., Y. Shen, Y. Luo, B. Wang, Z. Yang, and P. Guo, 2018: Observed surface radiation and temperature impacts from the large-scale deployment of photovoltaics in the barren area of Gonghe, China. Renewable Energy, 118, 131-137, https://doi.org/ 10.1016/j.renene.2017.11.007.

Chen, Y., A. Ebenstein, M. Greenstone, and H. Li, 2013: Evidence on the impact of sustained exposure to air pollution on life expectancy from China's Huai River policy. Proc. Natl. Acad. Sci. USA, 110, 12 936-12 941, https://doi.org/10.1073/ pnas.1300018110.

Chow, W. T., T. J. Volo, E. R. Vivoni, G. D. Jenerette, and B. L. Ruddell, 2014: Seasonal dynamics of a suburban energy balance in Phoenix, Arizona. Int. J. Climatol., 34, 3863-3880, https://doi.org/10.1002/joc.3947.

EIA, 2018a: Monthly energy review. United States Department of Energy, https://www.eia.gov/totalenergy/data/monthly/.

_ 2018b: Electric power monthly. United States Department of Energy, https://www.eia.gov/electricity/monthly/epm_table_ grapher.php?t=epmt_1_01_a.

Erell, E., V. Leal, and E. Maldonado, 2005: Measurement of air temperature in the presence of a large radiant flux: An assessment of passively ventilated thermometer screens. Bound.-Layer Meteor., 114, 205-231, https://doi.org/10.1007/s10546-004-8946-8.

Fthenakis, V., and E. Alsema, 2006: Photovoltaics energy payback times, greenhouse gas emissions and external costs: 2004-early 2005 status. Prog. Photovoltaics Res. Appl., 14, 275-280, https://doi.org/10.1002/pip.706.

_ , and Y. Yu, 2013: Analysis of the potential for a heat island effect in large solar farms. Proc. 2013 IEEE 39th Photovoltaic Specialists Conf., Tampa, FL, IEEE, 3362-3366, https:// doi.org/10.1109/PVSC.2013.6745171.

Grimmond, C. S. B., H. A. Cleugh, and T. R. Oke, 1991: An objective urban heat storage model and its comparison with other schemes. Atmos. Environ., 25B, 311-326, https://doi.org/ 10.1016/0957-1272(91)90003-W.

Hoegh-Guldberg, O., and J. F. Bruno, 2010: The impact of climate change on the world's marine ecosystems. Science, 328, 1523 1528, https://doi.org/10.1126/science.1189930.

Hsu, D. D., P. O'Donoughue, V. Fthenakis, G. A. Heath, H. C. Kim, P. Sawyer, J. K. Choi, and D. E. Turney, 2012: Life cycle greenhouse gas emissions of crystalline silicon photovoltaic electricity generation. J. Ind. Ecol., 16, S122-S135, https://doi.org/ 10.1111/j.1530-9290.2011.00439.x.

$\mathrm{Hu}, \mathrm{A}$. , and Coauthors, 2016: Impact of solar panels on global climate. Nat. Climate Change, 6, 290-294, https://doi.org/ 10.1038/nclimate2843.

Kastner-Klein, P., and M. W. Rotach, 2004: Mean flow and turbulence characteristics in an urban roughness sublayer. Bound.-Layer Meteor., 111, 55-84, https://doi.org/10.1023/B: BOUN.0000010994.32240.b1.

Lenzen, M., and J. Munksgaard, 2002: Energy and $\mathrm{CO}_{2}$ lifecycle analyses of wind turbines-Review and applications.
Renewable Energy, 26, 339-362, https://doi.org/10.1016/S09601481(01)00145-8.

Leuning, R., E. Van Gorsel, W. J. Massman, and P. R. Isaac, 2012: Reflections on the surface energy imbalance problem. Agric. For. Meteor., 156, 65-74, https://doi.org/10.1016/ j.agrformet.2011.12.002.

Li, D. H., L. Yang, and J. C. Lam, 2012: Impact of climate change on energy use in the built environment in different climate zones-A review. Energy, 42,103-112, https://doi.org/10.1016/ j.energy.2012.03.044.

Mahrt, L., 1998: Flux sampling errors for aircraft and towers. J. Atmos. Oceanic Technol., 15, 416-429, https://doi.org/ 10.1175/1520-0426(1998)015<0416:FSEFAA > 2.0.CO;2.

Masson, V., M. Bonhomme, J.-L. Salagnac, X. Briottet, and A. Lemonsu, 2014: Solar panels reduce both global warming and urban heat island. Front. Environ. Sci., 2, 14, https://doi.org/ 10.3389/fenvs.2014.00014

Mauder, M., and T. Foken, 2006: Impact of post-field data processing on eddy covariance flux estimates and energy balance closure. Meteor. Z., 15, 597-609, https://doi.org/10.1127/0941-2948/2006/ 0167.

Millstein, D., and S. Menon, 2011: Regional climate consequences of large-scale cool roof and photovoltaic array deployment. Environ. Res. Lett., 6, 034001, https://doi.org/10.1088/1748-9326/ 6/3/034001.

Offerle, B., C. S. B. Grimmond, and K. Fortuniak, 2005: Heat storage and anthropogenic heat flux in relation to the energy balance of a central European city centre. Int. J. Climatol., 25, 1405-1419, https://doi.org/10.1002/joc.1198.

Oke, T. R., G. Mills, A. Christen, and J. A. Voogt, 2017: Urban Climates. Cambridge University Press, 546 pp., https://doi.org/ 10.1017/9781139016476.

Pacala, S., and R. Socolow, 2004: Stabilization wedges: Solving the climate problem for the next 50 years with current technologies. Science, 305, 968-972, https://doi.org/10.1126/ science. 1100103.

Patz, J. A., D. Campbell-Lendrum, T. Holloway, and L. A. Foley, 2005: Impact of regional climate change on human health. Nature, 438, 310-317, https://doi.org/10.1038/nature04188.

Pehnt, M., 2006: Dynamic life cycle assessment (LCA) of renewable energy technologies. Renewable Energy, 31, 55-71, https://doi.org/10.1016/j.renene.2005.03.002.

Salamanca, F., M. Georgescu, A. Mahalov, M. Moustaoui, and A. Martilli, 2016: Citywide impacts of cool roof and rooftop solar photovoltaic deployment on near-surface air temperature and cooling energy demand. Bound.-Layer Meteor., 161, 203-221, https://doi.org/10.1007/s10546-016-0160-y.

Scherba, A., D. D. J. Sailor, T. N. Rosenstiel, and C. C. Wamser, 2011: Modeling impacts of roof reflectivity, integrated photovoltaic panels and green roof systems on sensible heat flux into the urban environment. Build. Environ., 46, 2542-2551, https://doi.org/10.1016/ j.buildenv.2011.06.012.

Schmidhuber, J., and F. N. Tubiello, 2007: Global food security under climate change. Proc. Natl. Acad. Sci. USA, 104, 19703-19708, https://doi.org/10.1073/pnas.0701976104.

Steeneveld, G. J., M. J. J. Wokke, C. D. Groot Zwaaftink, S. Pijlman, B. G. Heusinkveld, A. F. G. Jacobs, and A. M. M. Holtslag, 2010: Observations of the radiation divergence in the surface layer and its implication for its parameterization in numerical weather prediction models. J. Geophys. Res., 115, D06107, https://doi.org/10.1029/ 2009JD013074. 
Taha, H., 2013: The potential for air-temperature impact from largescale deployment of solar photovoltaic arrays in urban areas. Sol. Energy, 91, 358-367, https://doi.org/10.1016/j.solener.2012.09.014.

Tol, R. S., 2002: Estimates of the damage costs of climate change, Part II. Dynamic estimates. Environ. Resour. Econ., 21, 135-160, https://oi.org/10.1023/A:1014539414591.

Uludere Aragon, N., M. Wagner, M. Wang, A. M. Broadbent, N. Parker, and M. Georgescu, 2017: Sustainable land management for bioenergy crops. Energy Procedia, 125, 379-388, https://doi.org/10.1016/j.egypro.2017.08.063.

Walther, G. R., and Coauthors, 2002: Ecological responses to recent climate change. Nature, 416, 389-395, https://doi.org/ 10.1038/416389a.
Wang, M., M. Wu, and H. Huo, 2007: Life-cycle energy and greenhouse gas emission impacts of different corn ethanol plant types. Environ. Res. Lett., 2, 024001, https://doi.org/ 10.1088/1748-9326/2/2/024001.

Wheeler, T., and J. Von Braun, 2013: Climate change impacts on global food security. Science, 341, 508-513, https://doi.org/ 10.1126/science.1239402.

Wilczak, J. M., S. P. Oncley, and S. A. Stage, 2001: Sonic anemometer tilt correction algorithms. Bound.-Layer Meteor., 99, 127-150, https://doi.org/10.1023/A:1018966204465.

Wilson, K., and Coauthors, 2002: Energy balance closure at FLUXNET sites. Agric. For. Meteor., 113, 223-243, https:// doi.org/10.1016/S0168-1923(02)00109-0. 